\title{
FeSiBPNbCu Bulk Nanocrystalline Alloys with High GFA and Excellent Soft-Magnetic Properties
}

\author{
Lei Liu ${ }^{1,2}$, Bang Zhou ${ }^{2}$, Yiqun Zhang ${ }^{2,3}$, Aina He ${ }^{2,3}$, Tao Zhang ${ }^{4}$, Fushan Li ${ }^{1, *}$, \\ Yaqiang Dong ${ }^{2,3, *}$ and Xinmin Wang ${ }^{2}$ \\ 1 School of Materials Science and Engineering, Zhengzhou University, Zhengzhou 450001, China; \\ liulei123@nimte.ac.cn \\ 2 Zhejiang Province Key Laboratory of Magnetic Materials and Application Technology, \\ CAS Key Laboratory of Magnetic Materials and Devices, Ningbo Institute of Materials Technology \& \\ Engineering, Chinese Academy of Sciences, Ningbo 315201, China; zhoubang@nimte.ac.cn (B.Z.); \\ zhangyiqun@nimte.ac.cn (Y.Z.); hean@nimte.ac.cn (A.H.); wangxm@nimte.ac.cn (X.W.) \\ 3 College of Materials Science and Opto-Electronic Technology, University of Chinese Academy of Sciences, \\ Beijing 100049, China \\ 4 Key Laboratory of Aerospace Materials and Performance, School of Materials Science and Engineering, \\ Beihang University, Beijing 100191, China; zhangtao@buaa.edu.cn \\ * Correspondence: fsli@zzu.edu.cn (F.L.); dongyq@nimte.ac.cn (Y.D.); \\ Tel.: +86-183-3926-8360 (F.L.); +86-574-8761-7212 (Y.D.)
}

Received: 22 January 2019; Accepted: 8 February 2019; Published: 13 February 2019

\begin{abstract}
Fe}_{0.76} \mathrm{Si}_{0.09} \mathrm{~B}_{0.1} \mathrm{P}_{0.05}\right)_{99.3-x} \mathrm{Nb}_{x} \mathrm{Cu}_{0.7}(x=0-1.5$ at. \%) bulk nanocrystalline alloys were prepared to investigate the alloying effects of $\mathrm{Nb}$ on glass forming ability, thermal stability, soft magnetic properties, and crystallization behavior. It was found that the amorphous forming ability was greatly improved with the addition of minor $\mathrm{Nb}$. The thermal stability of $\mathrm{Nb}$-containing alloy was significantly improved because the initial crystallization temperature and crystallization activation of the primary phase were obviously better than that of the $\mathrm{Nb}$-free alloy. Further, the larger intervals of two-phase crystallization temperature and the significantly higher activation energy of crystallization of the second phase in the $\mathrm{Nb}$-containing alloys favor the formation of a single $\alpha$-Fe(Si) nanocrystalline structure. Moreover, $\mathrm{Nb}$-containing alloys exhibit excellent soft magnetic properties, including high saturation magnetization of 1.42-1.49 T, low coercivity of around $1.0 \mathrm{~A} / \mathrm{m}$, and high permeability of about 18,000 at $1 \mathrm{kHz}$, which makes the alloys promising soft magnetic materials for industrial applications.
\end{abstract}

Keywords: bulk nanocrystalline alloys; glass forming ability; high saturation magnetization; magnetic softness

\section{Introduction}

The energy crisis is the most serious problem in the development of the current world. Therefore, to improve efficiency and reduce power consumption, higher saturation magnetization $\left(B_{\mathrm{s}}\right)$ accompanied with excellent soft magnetic properties (SMPs) is strongly required for the magnetic materials used in electrical power supplies and a variety of other industries. Since the $\mathrm{Fe}_{73.5} \mathrm{Si}_{13.5} \mathrm{~B}_{9} \mathrm{Nb}_{3} \mathrm{Cu}_{1}$ (FINEMET) nanocrystalline alloy obtained through crystalization of the corresponding glassy precursors was first reported by Yoshizawa in 1988 [1], Fe-based nanocrystalline alloys have attracted great interest because of their excellent SMPs and extremely low core loss, and thus their low energy consumption and high efficiency [2,3]. Then, a wide variety of new alloys with improved SMPs for electronic and electric industries have been developed through composition adjustment and microstructure evolution, mainly focusing on the FeSiBNbCu, FeSiBCu, and FeSiBPCu 
alloy systems [1-7]. Much work has been devoted to studying the mechanism of the nanocrystalline microstructural evolution in these alloys. Hono et al. reported that $\mathrm{Cu}$ atoms formed clusters prior to the onset of the crystallization reaction in nanocrystalline $\mathrm{FeZrBCu}$ and $\mathrm{FeSiBNbCu}$ alloys [8]. By employing a three-dimensional atom probe and a high resolution electron microscope, it was further evidenced that $\mathrm{Cu}$ clusters were indirectly making contact with the $\alpha$ - $\mathrm{Fe}(\mathrm{Si})$ nanocrystals, suggesting that the $\alpha-\mathrm{Fe}(\mathrm{Si})$ particles heterogeneously nucleated at the site of $\mathrm{Cu}$ clusters [9]. As $\mathrm{Nb}$ was enriched in the remaining amorphous phase, the interface between $\alpha-\mathrm{Fe}(\mathrm{Si})$ and the amorphous phase could be clearly seen from the drastic change in the concentrations of $\mathrm{Nb}$, which suppressed the growth of $\alpha-\mathrm{Fe}(\mathrm{Si})$ grains.

The mechanical properties of metallic glass, including its intrinsic brittleness, make it difficult to be processed and formed, which seriously limits its practical application in engineering. As recent studies pointed out, the size effects of large ductility and yield strength can be activated for nanoscale thin film metallic glasses and even for micronscale ribbon ones, which exhibit excellent magnetic properties such as much lower magnetic loss than that of their bulk counterpart [10,11]. In fact, it is just thin film metallic glasses and small-scale ribbon ones that are widely used in the power and electronics industries because of their good machinability and formability. However, the glass forming ability (GFA) of these nanocrystalline alloys with high $B_{\mathrm{s}}$ is very low, with the critical diameter $\left(D_{\mathrm{cr}}\right)$ of fully amorphous rods of no more than $1 \mathrm{~mm}$. This has seriously hindered their further applications, so it is necessary to improve their GFA and SMPs simultaneously. Some attempts have been made to synthesize Fe-based bulk nanocrystalline alloys with high GFA and SMPs. Resultantly, a series of alloys have been successfully developed [12-18], which can be made into thick ribbons or nanocrystalline rod-shaped samples. Recently, by logically adding $\mathrm{Cu}, \mathrm{FeSiBPNbCu}$ alloys with high GFA and SMPs were successfully developed by our team [18]. Especially when 0.75 at. \% Cu was introduced into FeSiBPNb alloy, the alloy after nanocrystalline treatment showed superior SMPs and high GFA. In the combination of $\mathrm{Cu}$ and $\mathrm{Nb}$, as widely reported [1,9], $\mathrm{Cu}$ offers nucleation sites for the precipitation of the $\alpha-\mathrm{Fe}(\mathrm{Si})$ grains, while $\mathrm{Nb}$ impedes the growth and promotes these grains to exhibit a much finer scale. Our previous work investigated the influences of $\mathrm{Cu}$ element addition point on the GFA of $\left(\mathrm{Fe}_{0.76} \mathrm{Si}_{0.09} \mathrm{~B}_{0.1} \mathrm{P}_{0.05}\right)_{99} \mathrm{Nb}_{1}$ and found that the GFA of $\mathrm{Cu}$ doped alloys slightly increased with minor $\mathrm{Cu}$ addition. Especially for the alloys with $\mathrm{Cu}$ content below 1 at. \%, the GFA was strong enough to fabricate amorphous rods with diameters of over $1 \mathrm{~mm}$. Further, we tried to increase the content of Fe [19]. The results show that the magnetic saturation of the alloy increased gradually with the increase of iron content, but the GFA of the alloy deteriorated seriously. The increase of 0.02 at. \% was no longer sufficient for the preparation of bulk amorphous alloys. Therefore, it is very instructive to study the effect of $\mathrm{Nb}$ content on the comprehensive performance in industrial production. In this paper, with the aim of obtaining the high GFA, good SMPs and high $B_{\mathrm{s}}$ alloys, 0.7 at. \% $\mathrm{Cu}$ was identified as the optimum quantity for the FeSiBPCu system, and the effect of Nb content on the GFA, the SMPs, the thermal stability, and the microstructure of $\left(\mathrm{Fe}_{0.76} \mathrm{Si}_{0.09} \mathrm{~B}_{0.1} \mathrm{P}_{0.05}\right)_{99.3-x} \mathrm{Nb}_{x} \mathrm{Cu}_{0.7}(x=0-1.5)$ bulk nanocrystalline alloys were systematically studied.

\section{Experimental Procedures}

$\left(\mathrm{Fe}_{0.76} \mathrm{Si}_{0.09} \mathrm{~B}_{0.1} \mathrm{P}_{0.05}\right)_{99.3-x} \mathrm{Nb}_{x} \mathrm{Cu}_{0.7}(x=0-1.5)$ alloy ingots were melted by induction melting of pure $\mathrm{Fe}(99.99$ wt. \%), $\mathrm{Nb}(99.9$ wt. \%) and $\mathrm{Cu}(99.99$ wt. \%), crystalline Si (99.99 wt. \%) and B (99.9 wt. \%) metalloids, and $\mathrm{Fe}_{3} \mathrm{P}$ (99.9 wt. \%) pre-alloy (Zhongjin, Beijing, China) in a high-purity argon atmosphere. The compositions were nominally expressed in atomic percentage. Cylindrical alloy rods with a constant length of about $40 \mathrm{~mm}$ and different diameters ranging between 1 and $3 \mathrm{~mm}$ were produced by copper mold casting in an air atmosphere. Amorphous ribbons with a thickness of $22 \mu \mathrm{m}$ and a width of $1 \mathrm{~mm}$ were prepared by the single-roller melt spinning method. The thermal properties of as-cast ribbons were analyzed by differential scanning calorimeter (DSC, 404C, NETZSCH, Selb, Germany) at a heating rate of $0.67 \mathrm{~K} / \mathrm{s}$ in a high purity argon flow. The annealing temperature $\left(T_{\mathrm{a}}\right)$ for the ribbons were determined based on the crystallization temperatures $\left(T_{x}\right)$ obtained from the DSC 
test. Isothermal annealing was carried out under certain temperatures for $5 \mathrm{~min}$. On the basis of the DSC curves of as-cast specimens at the heating rates of $0.167,0.33,0.5$, and $0.67 \mathrm{~K} / \mathrm{s}$, the corresponding Kissinger plots of the specimens were used to calculate the activation energy $\left(E_{\mathrm{a}}\right)$.

The microstructures of ribbons were examined by X-ray diffraction (XRD, D8 Advance, Bruker, Karlsruhe, Germany) with $\mathrm{Cu}-\mathrm{K} \alpha$ radiation and high-resolution transmission electron microscopy (HRTEM, Tecnai G2 F20, FEI, Hillsboro, OR, USA). The samples for TEM observation were prepared by ion milling from both sides of the ribbons. Magnetic properties including $B_{\mathrm{s}}$, coercivity $\left(H_{\mathrm{c}}\right)$, and effective permeability $\left(\mu_{\mathrm{e}}\right)$ at $1 \mathrm{kHz}$ were measured with a vibrating sample magnetometer (VSM, 7410, Lake Shore, Columbus, OH, USA) under a maximum applied magnetic field of 800 kA/m, DC B-H loop tracer (BHS-40, Riken, Saitama, Japan) under a maximum field of 800 A/m, and an impedance analyzer (4294A, Agilent, PaloAlto, CA, USA) under a field of 1 A/m, respectively. All measurements were performed at room temperature.

\section{Results and Discussion}

The GFA of $\left(\mathrm{Fe}_{0.76} \mathrm{Si}_{0.09} \mathrm{~B}_{0.1} \mathrm{P}_{0.05}\right)_{99.3-x} \mathrm{Nb}_{x} \mathrm{Cu}_{0.7}$ bulk nanocrystalline alloys was estimated by the $D_{\mathrm{cr}}$ of amorphous rods. As shown in Figure 1, the XRD patterns show only a broad peak for $\mathrm{Nb}$-containing alloys, implying the formation of single amorphous structures, but the pattern of $\mathrm{Nb}$-free alloy shows strong crystal characteristics. The $D_{\mathrm{cr}}$ fell into the range of $1-2.5 \mathrm{~mm}$ with a changing trend that the $D_{\mathrm{cr}}$ increased from 1 to $2.5 \mathrm{~mm}$, then reduced to $2 \mathrm{~mm}$ depending on the amount of $\mathrm{Nb}$. The GFA was significantly enhanced with minor $\mathrm{Nb}$ addition, and the adequate $\mathrm{Nb}$ content for the maximum GFA was less than 1 at. \% in the alloys. According to the empirical rules of high GFA glass alloys, the addition of $\mathrm{Nb}$ caused the more sequential change in the atomic size order, as well as the generation of new atomic pairs with various larger negative heats of mixing between $\mathrm{Nb}$ and (Fe, Si, B, P) atomic pairs [20]. Subsequently, a new liquid structure with strong interaction formed and the stronger bonding nature of $\mathrm{Nb}-(\mathrm{Fe}, \mathrm{Si}, \mathrm{B}, \mathrm{P})$ atomic pairs was beneficial to suppressing the nucleation and growth reactions of a crystalline phase, leading to the increase in glass transition temperature $\left(T_{\mathrm{g}}\right)$ and a supercooled liquid region $\left(\Delta T_{x}=T_{x}-T_{\mathrm{g}}\right)[18,19]$, which can be confirmed by Figure 2. However, the decreases in the GFA could also be attributed to the bonding nature, which becomes too strong when the $\mathrm{Nb}$ content is over 1 at. \% [20].

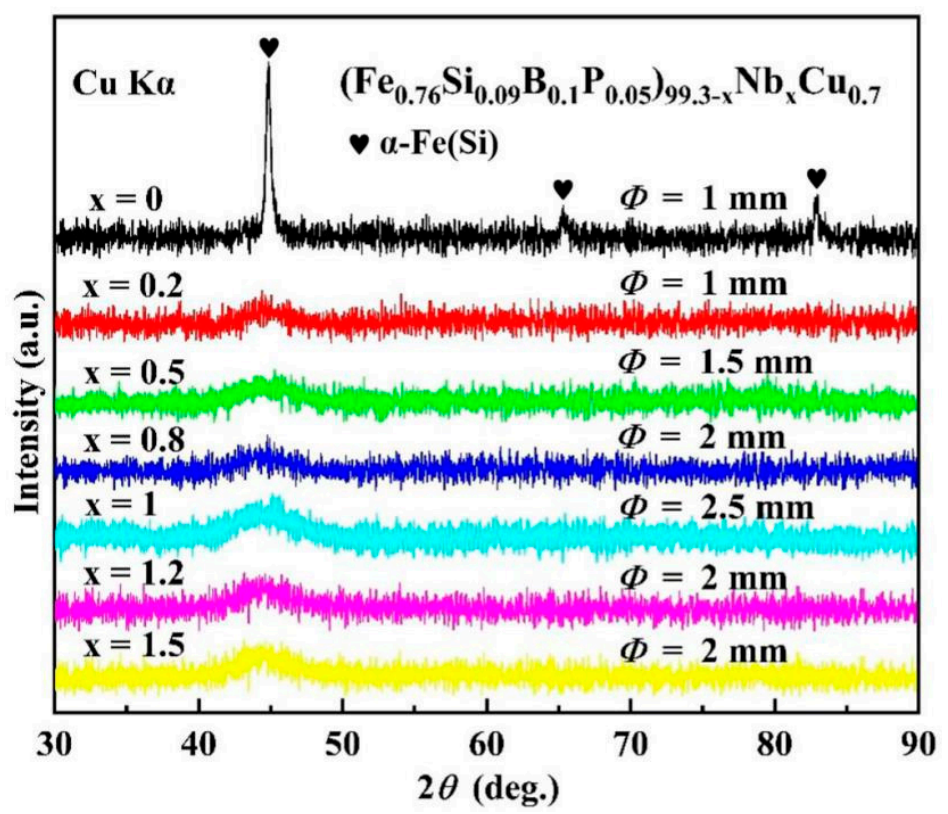

Figure 1. XRD patterns of the as-cast $\left(\mathrm{Fe}_{0.76} \mathrm{Si}_{0.09} \mathrm{~B}_{0.1} \mathrm{P}_{0.05}\right)_{99.3-x} \mathrm{Nb}_{x} \mathrm{Cu}_{0.7}(x=0,0.2,0.5,0.8,1.0,1.2$, 1.5) rods with different diameters. 

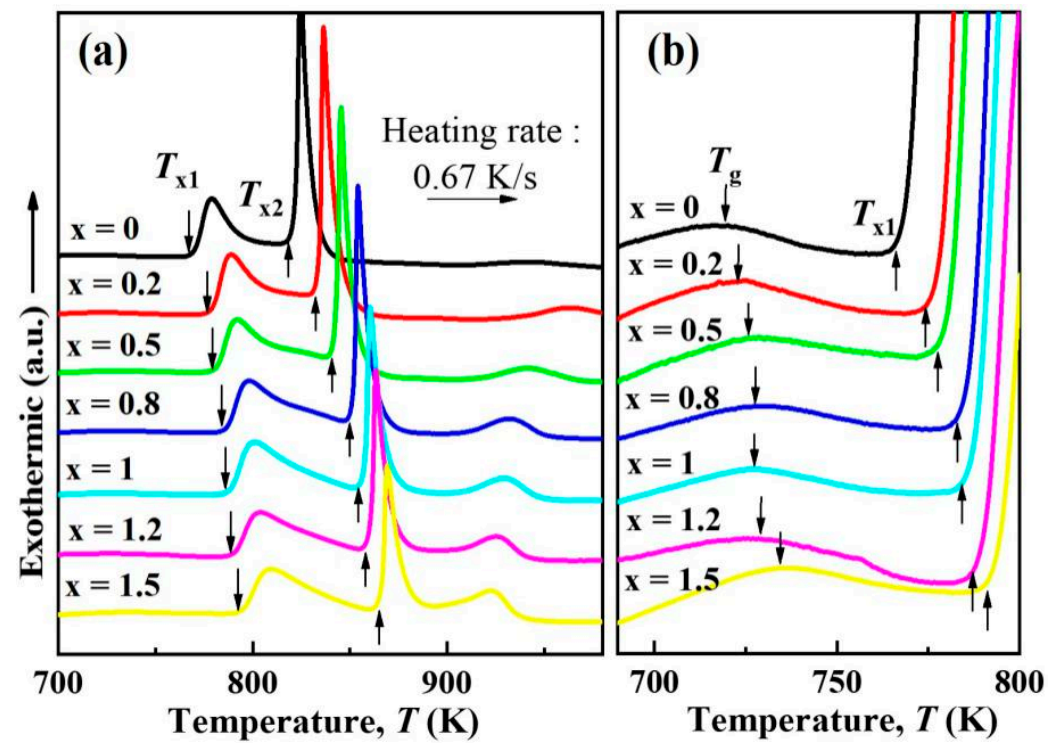

Figure 2. (a) DSC curves of the as-cast $\left(\mathrm{Fe}_{0.76} \mathrm{Si}_{0.09} \mathrm{~B}_{0.1} \mathrm{P}_{0.05}\right)_{99.3-x} \mathrm{Nb}_{x} \mathrm{Cu}_{0.7}(x=0,0.2,0.5,0.8,1.0$, $1.2,1.5)$ ribbons heated at a rate of $0.67 \mathrm{~K} / \mathrm{s}$. (b) Enlarged DSC curves showing the supercooled liquid region.

The thermal properties of as-cast ribbons were estimated by DSC at a heating rate of $0.67 \mathrm{~K} / \mathrm{s}$, as shown in Figure 2. The pattern of $\mathrm{Nb}$-free alloy exhibits a distinct temperature range between the first and second exothermic peaks and a large area followed by the first crystallization peak, which means that a massive number of $\alpha-\mathrm{Fe}(\mathrm{Si})$ crystals were precipitated. This indicates that the $\left(\mathrm{Fe}_{0.76} \mathrm{Si}_{0.09} \mathrm{~B}_{0.1} \mathrm{P}_{0.05}\right)_{99.3} \mathrm{Cu}_{0.7}$ alloy is an excellent candidate for nanocrystallization. However, the low initial crystallization temperature $\left(T_{x 1}=679 \mathrm{~K}\right)$ and relatively small supercooled liquid region implies low thermal stability against crystallization and thus low GFA. However, the $T_{x 1}$ increased by $27 \mathrm{~K}$ when the $\mathrm{Nb}$ content was up to 1.5 at. \%, indicating the significant enhancement of stability. All the samples exhibited observable $\Delta T_{x}$ and followed a trend (initially increasing with the amount of $\mathrm{Nb}$, followed by decreasing), as shown in Figure $2 b$, with the maximum value of $67 \mathrm{~K}$ when the amount of $\mathrm{Nb}$ reached 1 at. \%. The large $\Delta T_{x}$ favored the high GFA in the $\mathrm{Nb}$-containing alloys. Furthermore, the patterns of all the $\mathrm{Nb}$-containing alloys exhibit obvious intervals between the first two exothermic peak temperatures $T_{x 2}$ and $T_{x 1}$, which is defined as $\Delta T\left(\Delta T=T_{x 2}-T_{x 1}\right)$. The $\Delta T$ expanded gradually to about $70 \mathrm{~K}$ with the addition of 1.5 at. $\% \mathrm{Nb}$.

In order to further investigate the effect of $\mathrm{Nb}$ on the thermal stability and crystallization process, the activation energy $\left(E_{\mathrm{a}}\right)$ of $\alpha-\mathrm{Fe}(\mathrm{Si})$ and $\mathrm{Fe}-(\mathrm{B}, \mathrm{P})$ phases, represented as $E_{\mathrm{a} 1}$ and $E_{\mathrm{a} 2}$, was derived by kinetic analyses. On the basis of the DSC curves of as-cast ribbons at the heating rates of $0.167,0.33$, 0.5 , and $0.67 \mathrm{~K} / \mathrm{s}$, the corresponding Kissinger plots of the specimens were constructed through the Kissinger method [21]:

$$
\ln \left(T_{p}^{2} / \beta\right)=E_{a} /\left(R T_{p}\right)+\ln \left(E_{a} / R\right)-\ln v
$$

where $\beta, R, E_{\mathrm{a}}, v$, and $T_{\mathrm{p}}$ are the heating rate, gas constant, action energy, frequency factor, and peak temperature of crystallization, respectively. As seen in Figure 3, $E_{\mathrm{a} 1}$ and $E_{\mathrm{a} 2}$ were calculated as 280.2 and $413.6 \mathrm{~kJ} / \mathrm{mol}$, respectively, for the $\left(\mathrm{Fe}_{0.76} \mathrm{Si}_{0.09} \mathrm{~B}_{0.1} \mathrm{P}_{0.05}\right)_{99.3} \mathrm{Cu}_{0.7}$ alloy, and 368.9 and $576.3 \mathrm{~kJ} / \mathrm{mol}$, respectively, for the $\left(\mathrm{Fe}_{0.76} \mathrm{Si}_{0.09} \mathrm{~B}_{0.1} \mathrm{P}_{0.05}\right)_{98.8} \mathrm{Nb}_{0.5} \mathrm{Cu}_{0.7}$ alloy. The activation energy of the $\mathrm{Nb}$-containing $(0.5$ at. \%) alloy is much higher than that of its counterpart $\mathrm{Nb}$-free sample. Therefore, it is more stable to maintain the amorphous structure of the $\mathrm{Nb}$-containing alloy. Moreover, the $\Delta E_{\mathrm{a}}\left(\Delta E_{\mathrm{a}}=E_{\mathrm{a} 2}-E_{\mathrm{a} 1}\right)$ of the $\mathrm{Nb}$-containing alloy $(207.4 \mathrm{~kJ} / \mathrm{mol})$ is higher than the $\mathrm{Nb}$-free alloy $(133.4 \mathrm{~kJ} / \mathrm{mol})$ and this is more conducive to maintaining the $\alpha-\mathrm{Fe}(\mathrm{Si})$ single-phase structure of the alloy. These improvements are mainly due to the existence of $\mathrm{Nb}$ [22]. The weak diffusion ability of $\mathrm{Nb}$ atoms and enrichment in the interface between $\alpha-\mathrm{Fe}(\mathrm{Si})$ and the amorphous phases greatly 
suppress the growth of grains. Furthermore, $\mathrm{Nb}$ has a strong affinity with $\mathrm{B}$ and $\mathrm{P}$, making the $E_{\mathrm{a}}$ much higher $[18,21,22]$.

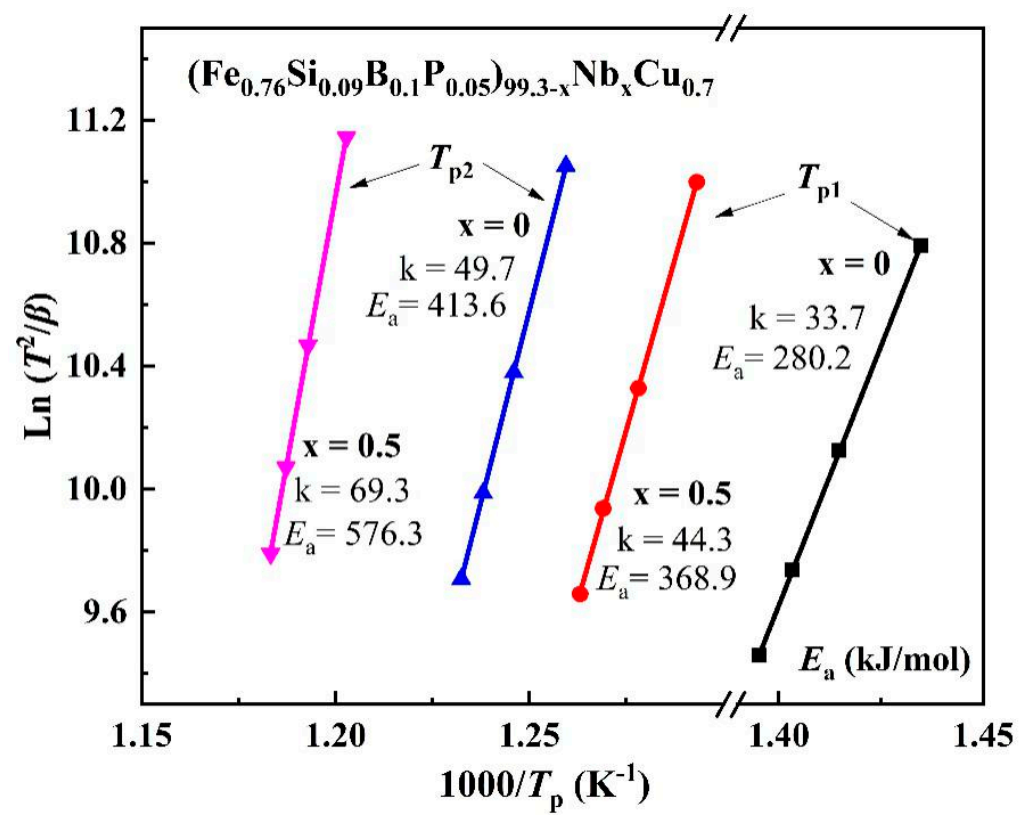

Figure 3. Kissinger plots for the $\left(\mathrm{Fe}_{0.76} \mathrm{Si}_{0.09} \mathrm{~B}_{0.1} \mathrm{P}_{0.05}\right)_{99.3-x} \mathrm{Nb}_{x} \mathrm{Cu}_{0.7}(x=0$ and 0.5$)$ ribbons.

The changes in the structure of the $\mathrm{Nb}$-containing amorphous alloy with annealing crystallization were examined by XRD, as shown in Figure 4. The alloy remained in the amorphous state until annealed at $743 \mathrm{~K}$ for $5 \mathrm{~min}$. As $T_{\mathrm{a}}$ rose to $763 \mathrm{~K}$, there was only the $\alpha-\mathrm{Fe}(\mathrm{Si})$ phase and no other crystallization phases for the alloy could be observed until $T_{\mathrm{a}}$ increased to $803 \mathrm{~K}$. When $T_{\mathrm{a}}$ was elevated to $823 \mathrm{~K}$, the other diffraction peaks emerged, which was in accordance with that of the $\mathrm{Fe}_{3}(\mathrm{~B}, \mathrm{P})$ phase [18]. The structures of the $\mathrm{Nb}$-containing amorphous alloy after annealing at 783, 803, and $823 \mathrm{~K}$ for $5 \mathrm{~min}$ were further examined by TEM. After annealing at $783 \mathrm{~K}$ for $5 \mathrm{~min}$, as shown in Figure $5 \mathrm{a}$, the crystallization phase is identified as $\alpha-\mathrm{Fe}(\mathrm{Si})$ from the the selected area electron diffraction (SAED) patterns in Figure $5 \mathrm{~d}$. The $\alpha-\mathrm{Fe}(\mathrm{Si})$ grains had an average size of approximately $19 \mathrm{~nm}$, randomly dispersing in the residual amorphous matrix. It can be seen from the TEM image of Figure $5 b$ that the volume fraction of the crystallization phase obviously increased and the residual amorphous matrix relatively decreased when annealed at $803 \mathrm{~K}$, owing to the continuous precipitation and growth of grains. The average size increased to $22 \mathrm{~nm}$ and there were not just $\alpha-\mathrm{Fe}(\mathrm{Si}) \mathrm{grains}$, but a few $\mathrm{Fe}_{3}(\mathrm{~B}, \mathrm{P})$ grains in the crystallization products, which can be identified from Figure $5 \mathrm{~d}$, but failed to be observed by XRD, as shown in Figure 4, as a result of its limited resolution. As $T_{\mathrm{a}}$ increased to $823 \mathrm{~K}$ (Figure $5 \mathrm{c}$ ), the amorphous matrix had almost disappeared, and the $\alpha-\mathrm{Fe}(\mathrm{Si})$ and $\mathrm{Fe}_{3}(\mathrm{~B}, \mathrm{P})$ grains dispersed randomly with an average size of approximately $25 \mathrm{~nm}$. Meanwhile, the heat enthalpy $(\Delta H)$ for the two discussed phases decreased continually, meaning the decreasing of the residual amorphous phase, as shown in Figure 5e. The disappearance of the first exothermic peak with $T_{\mathrm{a}}$ indicates that the crystallization of $\alpha-\mathrm{Fe}(\mathrm{Si})$ had finished completely, then the second phase began to dominate the crystallization process. In summary, the crystallization evolution of $\left(\mathrm{Fe}_{0.76} \mathrm{Si}_{0.09} \mathrm{~B}_{0.1} \mathrm{P}_{0.05}\right)_{98.8} \mathrm{Nb}_{0.5} \mathrm{Cu}_{0.7}$ ribbon can be summarized as follows:

$$
\mathrm{AM} \rightarrow \mathrm{AM}^{\prime}+\alpha-\mathrm{Fe}(\mathrm{Si})(763 \mathrm{~K}) \rightarrow \mathrm{AM}^{\prime \prime}+\alpha-\mathrm{Fe}(\mathrm{Si})+\mathrm{Fe}_{3}(\mathrm{~B}, \mathrm{P})(803 \mathrm{~K}) .
$$

It can be speculated from the above results that during the annealing process of $\left(\mathrm{Fe}_{0.76} \mathrm{Si}_{0.09} \mathrm{~B}_{0.1} \mathrm{P}_{0.05}\right)_{98.8} \mathrm{Nb}_{0.5} \mathrm{Cu}_{0.7}$, an apparent short-medium range ordering or a nanoscale phase separation came out from the amorphous matrix [23,24], which acted as the nucleation sites 
for $\alpha-\mathrm{Fe}(\mathrm{Si})$ crystals and led to the refinement of the grains. The introduction of $\mathrm{Cu}$ effectively stimulated the precipitation of the $\alpha-\mathrm{Fe}(\mathrm{Si})$ nanocrystalline phase, but the addition of $\mathrm{Nb}$ significantly inhibited nucleation and growth of grains, then favored the improvement of GFA for the present system [22,25]. Meanwhile, the right amount of $\mathrm{Nb}$ addition successfully promoted the acquisition of single and uniform fine $\alpha$ - $\mathrm{Fe}(\mathrm{Si})$ grains. Furthermore, $\mathrm{Nb}$ played a radical role in this Fe-based bulk nanocrystalline alloys in promoting the formation of $\alpha-\mathrm{Fe}(\mathrm{Si})$ nanocrystallites and suppressing compounds such as the $\left(\mathrm{Fe}_{3}(\mathrm{~B}, \mathrm{P})\right)$, hence producing the high-level SMPs of the alloys [26-28].

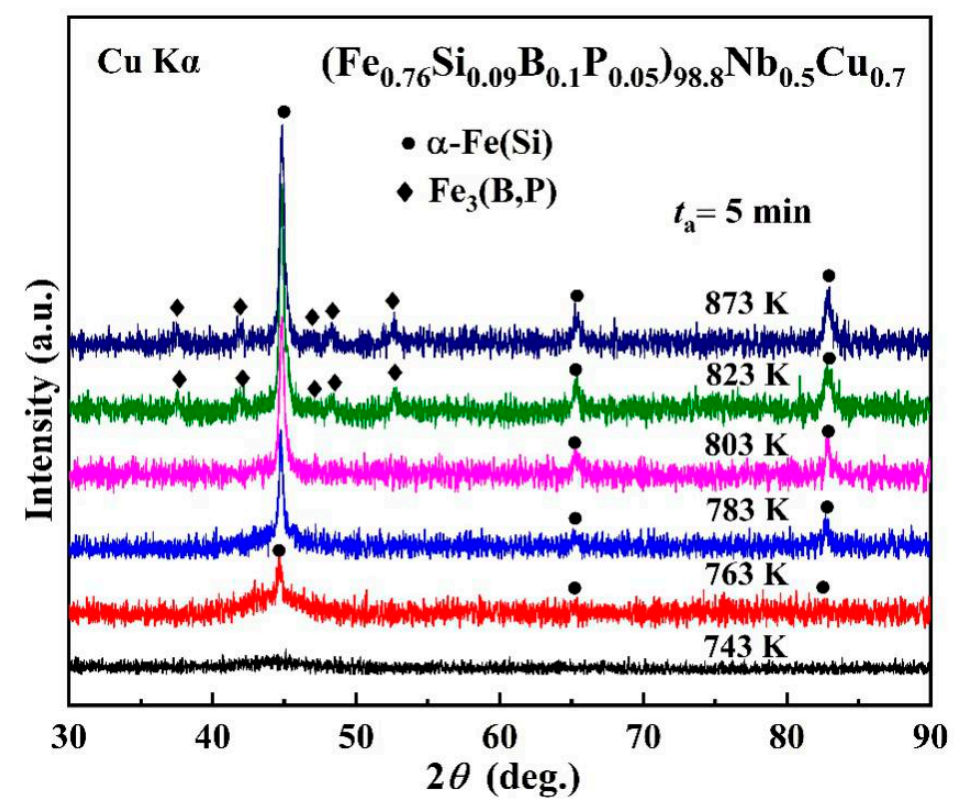

Figure 4. $\mathrm{XRD}$ patterns for the $\left(\mathrm{Fe}_{0.76} \mathrm{Si}_{0.09} \mathrm{~B}_{0.1} \mathrm{P}_{0.05}\right)_{98.8} \mathrm{Nb}_{0.5} \mathrm{Cu}_{0.7}$ ribbons after being annealed under several temperatures for $5 \mathrm{~min}$, respectively.



Figure 5. TEM bright field images and grain size distribution for the $\left(\mathrm{Fe}_{0.76} \mathrm{Si}_{0.09} \mathrm{~B}_{0.1} \mathrm{P}_{0.05}\right)_{98.8} \mathrm{Nb}_{0.5} \mathrm{Cu}_{0.7}$ alloy annealed for 5 min under the following: (a) $783 \mathrm{~K}$, (b) $803 \mathrm{~K}$, and (c) $823 \mathrm{~K}$; (d) SAED patterns I, II, and III corresponding to $783 \mathrm{~K}, 803 \mathrm{~K}$, and $823 \mathrm{~K}$, respectively; and (e) DSC curves of the annealed ribbons. 
Figure 6 illustrates the influences of $\mathrm{Nb}$ on $B_{\mathrm{s}}$ and $H_{\mathrm{c}}$ with different $T_{\mathrm{a}}$ for the $\left(\mathrm{Fe}_{0.76} \mathrm{Si}_{0.09} \mathrm{~B}_{0.1} \mathrm{P}_{0.05}\right)_{99.3-x} \mathrm{Nb}_{x} \mathrm{Cu}_{0.7}(x=0-1.5)$ alloys. Both the $B_{\mathrm{s}}$ and $H_{\mathrm{c}}$ of the $\mathrm{Nb}$-containing alloys showed a trend of decreasing with $\mathrm{Nb}$ addition in quenched state or annealed state at different $T_{\mathrm{a}}$. For both the $\mathrm{Nb}$-containing alloy and the $\mathrm{Nb}$-free one, the $B_{\mathrm{s}}$ changed (Figure $6 \mathrm{a}$ ) in the trend of increasing first and then decreasing with $T_{\mathrm{a}}$, while the change of $H_{\mathrm{c}}$ (Figure $6 \mathrm{~b}$ ) showed a contrary trend with the change of $B_{\mathrm{s}}$. There were no distinct differences in the rate and extent of $B_{\mathrm{s}}$ change between the $\mathrm{Nb}$-containing alloy and the $\mathrm{Nb}$-free one. As the content of $\mathrm{Nb}$ increased, $B_{\mathrm{s}}$ increased gradually to the maximum, followed by a slow decrease with $T_{\mathrm{a}}$ going up. Different from the trend of $B_{\mathrm{s}}, H_{\mathrm{c}}$ dropped a lot in the early stage and then slowly decreased to the minimum value and finally increased sharply. Usually, the features of $B_{\mathrm{s}}$ and $H_{\mathrm{c}}$ are considered to be caused by the relaxation of internal stress triggered by low temperature annealing and the appearance of crystallization phases activated by high temperature annealing. When annealed at a low temperature far below $T_{x 1}$, the increase in $B_{\mathrm{s}}$ is mainly attributed to the reduction of free volume and thus the increase of density caused by structure relaxation, while the decrease in $H_{\mathrm{c}}$ is the result of the enhancement of the magnetic isotropy accompanying the internal stress relaxation or removal $[29,30]$. If annealed at a high temperature over the crystallization peak, the ferroboron phase or ferrophosphorus phase begins to dominate the crystallization process, which is detrimental to SMPs, that is, resulting in the decrease in $B_{\mathrm{s}}$ and the increase in $H_{\mathrm{c}}$. Thus, the selectable $T_{\mathrm{a}}$ is usually limited within the temperature range of the first crystallization peak, in which the precipitation and growth of fine nano- $\alpha-\mathrm{Fe}(\mathrm{Si})$ grains are the objective of optimizing annealing technique. However, the present work indicates that the results of the actual isothermal treatment are quite different from those under the condition of ascending temperature annealing.

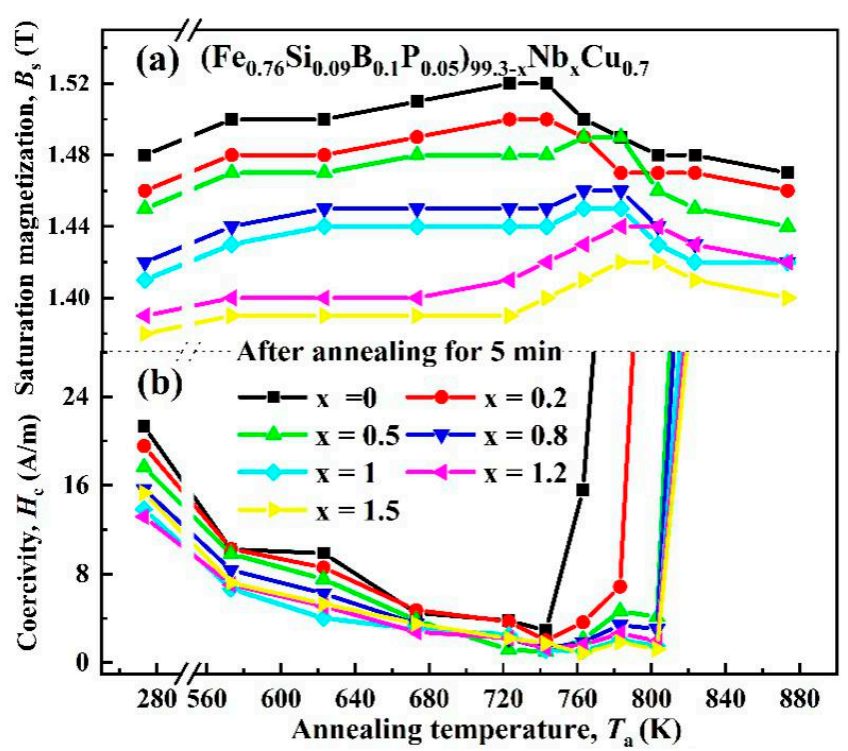

Figure 6. (a) $B_{\mathrm{s}}$ and (b) $H_{\mathrm{c}}$ of $\left(\mathrm{Fe}_{0.76} \mathrm{Si}_{0.09} \mathrm{~B}_{0.1} \mathrm{P}_{0.05}\right)_{99.3-x} \mathrm{Nb}_{x} \mathrm{Cu}_{0.7}(x=0-1.5)$ ribbons dependences on $T_{\mathrm{a}}$ annealed for $5 \mathrm{~min}$.

As shown in Figure 2, the crystallization temperature of isothermal annealing was significantly lower (about $20-30 \mathrm{~K}$ ) than that of ascending temperature annealing, which corresponds to $T_{x 1}$ obtained by the corresponding DSC. After annealing in the temperature range of $723-783 \mathrm{~K}$, the $\mathrm{Nb}$-containing alloys showed synthetically excellent SMPs, as shown in Figure 6. Moreover, from Figures 2 and 5, it can be seen that the full removal of stress by annealing in this temperature range resulted in significant improvement of $H_{\mathrm{c}}$ and $B_{\mathrm{s}}$. The emergence of fine nanocrystals, caused by annealing at higher temperature at this stage, further improved $B_{\mathrm{s}}$ and $H_{\mathrm{c}}[31,32]$. However, the $H_{\mathrm{c}}$ increased rapidly and the $B_{\mathrm{s}}$ began to decrease upon the emergence of $\mathrm{Fe}_{3}(\mathrm{~B}, \mathrm{P})$, resulting from annealing at $T_{\mathrm{a}}$ of $783 \mathrm{~K}$ or higher. 
Table 1 lists the GFA $\left(D_{\mathrm{cr}}\right)$ and Magnetic Properties $\left(H_{\mathrm{c}}, B_{\mathrm{s}}\right.$, and $\left.\mu_{\mathrm{e}}\right)$ of the alloys developed in this work and some other Fe-based bulk nanocrystalline alloys widely reported previously $[1,9,13]$. The developed FeSiBPNbCu bulk nanocrystalline alloys with minor $\mathrm{Nb}$ addition show comprehensively excellent properties, especially for the combination of high GFA and high $B_{\mathrm{S}}$, namely, $D_{\mathrm{cr}}$ of $1-2.5 \mathrm{~mm}$ and high $B_{\mathrm{s}}$ of $1.42-1.5 \mathrm{~T}$, but also low $H_{\mathrm{c}}$ of $0.86-2 \mathrm{~A} / \mathrm{m}$, high $\mu_{\mathrm{e}}$ at $1 \mathrm{kHz}$ of $15,000-18,500$. Owing to these advantages, the present alloys are encouraging for future progress as excellent soft magnetic materials.

Table 1. $D_{\mathrm{cr}}$ and magnetic properties of the present alloys and some Fe-based bulk metallic alloys reported previously.

\begin{tabular}{ccccc}
\hline & & \multicolumn{3}{c}{ Magnetic Properties } \\
\cline { 3 - 5 } Composition (at. \%) & $\boldsymbol{D}_{\mathbf{c r}}(\mathbf{m m})$ & $\boldsymbol{B}_{\mathbf{s}} \mathbf{( T )}$ & $\boldsymbol{H}_{\mathbf{c}}(\mathbf{A} / \mathbf{m})$ & $\boldsymbol{\mu}_{\mathbf{e}}$ \\
\hline $\mathrm{Fe}_{73.5} \mathrm{Si}_{13.5} \mathrm{~B}_{9} \mathrm{Nb}_{3} \mathrm{Cu}_{1}[1]$ & $<1$ & 1.24 & 0.53 & 100,000 \\
$\mathrm{Fe}_{72.5} \mathrm{Si}_{10} \mathrm{~B}_{12.5} \mathrm{Nb}_{4} \mathrm{Cu}_{1}[13]$ & 0.5 & 1.21 & 1.8 & - \\
$\mathrm{Fe}_{61.5} \mathrm{Co}_{10} \mathrm{~B}_{13.5} \mathrm{Si}_{10} \mathrm{Nb}_{4} \mathrm{Cu}_{1}[9]$ & 1.5 & 1.26 & 5 & - \\
& $T h e$ present alloys: & & & \\
$\left(\mathrm{Fe}_{0.76} \mathrm{Si}_{0.09} \mathrm{~B}_{0.1} \mathrm{P}_{0.05}\right)_{99.1} \mathrm{Nb}_{0.2} \mathrm{Cu}$ & & 1 & 2 & 15,600 \\
$\left(\mathrm{Fe}_{0.76} \mathrm{Si}_{0.09} \mathrm{~B}_{0.1} \mathrm{P}_{0.05}\right)_{98.8} \mathrm{Nb}_{0.5} \mathrm{Cu}_{0.7}$ & 1.5 & 1.49 & 0.96 & 18,500 \\
$\left(\mathrm{Fe}_{0.76} \mathrm{Si}_{0.09} \mathrm{~B}_{0.1} \mathrm{P}_{0.05}\right)_{98.5} \mathrm{Nb}_{0.8} \mathrm{Cu}_{0.7}$ & 2 & 1.46 & 1.28 & 17,800 \\
$\left(\mathrm{Fe}_{0.76} \mathrm{Si}_{0.09} \mathrm{~B}_{0.1} \mathrm{P}_{0.05}\right)_{98.3} \mathrm{Nb}_{1} \mathrm{Cu}_{0.7}$ & 2.5 & 1.45 & 1.02 & 15,500 \\
$\left(\mathrm{Fe}_{0.76} \mathrm{Si}_{0.09} \mathrm{~B}_{0.1} \mathrm{P}_{0.05}\right)_{98.1} \mathrm{Nb}_{1.2} \mathrm{Cu}_{0.7}$ & 2 & 1.44 & 1.3 & 17,800 \\
$\left(\mathrm{Fe}_{0.76} \mathrm{Si}_{0.09} \mathrm{~B}_{0.1} \mathrm{P}_{0.05}\right)_{97.8} \mathrm{Nb}_{1.5} \mathrm{Cu}_{0.7}$ & 2 & 1.42 & 0.86 & 16,900 \\
\hline
\end{tabular}

\section{Conclusions}

FeSiBPNbCu bulk nanocrystalline alloys with high GFA and excellent SMPs were successfully prepared. The feature of crystallization kinetic proved that the addition of $\mathrm{Nb}$ significantly improved the thermal stability. It was indicated that the results of the actual isothermal treatment are quite different from those under the condition of ascending temperature annealing. The crystallization temperature of isothermal annealing is significantly lower than that of ascending temperature annealing. The present alloys with minor $\mathrm{Nb}$ addition exhibited comprehensively excellent SMPs in both amorphous and nanocrystalline states. Moreover, the alloys developed in this work maintained excellent SMPs over a relatively wide $T_{\mathrm{a}}$ range, which makes them competitive candidates in future applications.

Author Contributions: Conceptualization, F.L. and Y.D.; methodology, L.L. and A.H.; validation, F.L.; formal analysis, L.L. and F.L.; investigation, L.L. and F.L.; resources, Y.D. and X.W.; data curation, L.L. and F.L.; writing—original draft preparation, L.L.; writing—review and editing, F.L. and Y.D.; visualization, B.Z. and Y.Z.; supervision, A.H. and T.Z.; project administration, F.L.; funding acquisition, F.L.

Funding: This work was supported by The National Key Research and Development Program of China (Grant No. 2016YFB0300500); National Natural Science Foundation of China (Grant No. 51601205, 51701183, U1704159, 51571047); and Zhejiang Provincial Natural Science Foundation (Grant No. LQ18E010006).

Conflicts of Interest: The authors declare no conflict of interest.

\section{References}

1. Yoshizawa, Y.; Oguma, S.; Yamauchi, K. New Fe-based soft magnetic alloys composed of ultrafine grain structure. J. Appl. Phys. 1988, 64, 6044-6046. [CrossRef]

2. Gheiratmand, T.; Hosseini, H.R.M. Finemet nanocrystalline soft magnetic alloy: Investigation of glass forming ability, crystallization mechanism, production techniques, magnetic softness and the effect of replacing the main constituents by other elements. J. Magn. Magn. Mater. 2016, 408, 177-192. [CrossRef]

3. Herzer, G. Modern soft magnets: Amorphous and nanocrystalline materials. Acta Mater. 2013, 61, 718-734. [CrossRef] 
4. Wang, Y.C.; Zhang, Y.; Takeuchi, A.; Makino, A.; Kawazoe, Y. Investigation on the crystallization mechanism difference between FINEMET (R) and NANOMET (R) type Fe-based soft magnetic amorphous alloys. J. Appl. Phys. 2016, 120, 6. [CrossRef]

5. Ohta, M.; Yoshizawa, Y. Magnetic properties of nanocrystalline $\mathrm{Fe}_{82.65} \mathrm{Cu}_{1.35} \mathrm{Si}_{x} \mathrm{~B}_{16-x}$ alloys $(x=0-7)$. Appl. Phys. Lett. 2007, 91, 062517. [CrossRef]

6. Makino, A.; Men, H.; Kubota, T.; Yubuta, K.; Inoue, A. New Fe-metalloids based nanocrystalline alloys with high Bs of 1.9T and excellent magnetic softness. J. Appl. Phys. 2009, 105. [CrossRef]

7. Yu, Q.; Wang, X.D.; Lou, H.B.; Cao, Q.P.; Jiang, J.Z. Atomic packing in Fe-based metallic glasses. Acta Mater. 2016, 102, 116-124. [CrossRef]

8. Matsuura, M.; Nishijima, M.; Takenaka, K.; Takeuchi, A.; Ofuchi, H.; Makino, A. Evolution of fcc Cu clusters and their structure changes in the soft magnetic $\mathrm{Fe}_{85.2} \mathrm{Si}_{1} \mathrm{~B}_{9} \mathrm{P}_{4} \mathrm{Cu}_{0.8}$ (NANOMET) and FINEMET alloys observed by X-ray absorption fine structure. J. Appl. Phys. 2015, 117, 4. [CrossRef]

9. Hono, K.; Ping, D.H.; Ohnuma, M.; Onodera, H. Cu clustering and Si partitioning in the early crystallization stage of an $\mathrm{Fe}_{73.5} \mathrm{Si}_{13.5} \mathrm{~B}_{9} \mathrm{Nb}_{3} \mathrm{Cu}_{1}$ amorphous alloy. Acta Mater. 1999, 47, 997-1006. [CrossRef]

10. Ghidelli, M.; Idrissi, H.; Sébastien, G.; Blandin, J.J.; Raskin, J.P.; Schryvers, D.; Pardoen, T. Homogeneous flow and size dependent mechanical behavior in highly ductile $\mathrm{Zr}_{65} \mathrm{Ni}_{35}$, metallic glass films. Acta Mater. 2017, 131, 246-259. [CrossRef]

11. Tian, L.; Cheng, Y.Q.; Shan, Z.W.; Li, J.; Wang, C.C.; Han, X.D.; Sun, J.; Ma, E. Approaching the ideal elastic limit of metallic glasses. Nat. Commun. 2012, 3, 609. [CrossRef] [PubMed]

12. Aykol, M.; Akdeniz, M.V.; Mekhrabov, A.O. Solidification behavior, glass forming ability and thermal characteristics of soft magnetic Fe-Co-B-Si-Nb-Cu bulk amorphous alloys. Intermetallics 2011, 19, 1330-1337. [CrossRef]

13. Stoica, M.; Roth, S.; Eckert, J.; Karan, T.; Ram, S.; Vaughan, G.; Yavari, A.R. FeCoBSiNb bulk metallic glasses with $\mathrm{Cu}$ additions. Phys. Status Solidi C 2010, 7, 1331-1335. [CrossRef]

14. Li, J.F.; Shao, Y.; Liu, X.; Yao, K.F. Fe-based bulk amorphous alloys with high glass formation ability and high saturation magnetization. Sci. Bull. 2015, 60, 396-399. [CrossRef]

15. Inoue, A.; Shen, B.; Ohsuna, T. Soft magnetic properties of nanocystalline Fe-Si-B-Nb-Cu rod alloys obtained by crystallization of cast amorphous phase. Mater. Trans. 2002, 43, 2337-2341. [CrossRef]

16. Shi, M.; Li, R.; Wang, J.; Liu, Z.; Luo, X.; Zhang, T. Effects of minor Cu addition on glass-forming ability and magnetic properties of FePCBCu alloys with high saturation magnetization. Philos. Mag. 2013, 93, $2182-2189$. [CrossRef]

17. Li, H.X.; Gao, J.E.; Wu, Y.; Jiao, Z.B.; Ma, D.; Stoica, A.D.; Wang, X.L.; Ren, Y.; Miller, M.K.; Lu, Z.P. Enhancing glass-forming ability via frustration of nano-clustering in alloys with a high solvent content. Sci Rep. 2013, 3, 1983. [CrossRef]

18. Li, Z.; Wang, A.; Chang, C.; Wang, Y.; Dong, B.; Zhou, S. FeSiBPNbCu alloys with high glass-forming ability and good soft magnetic properties. Intermetallics 2014, 54, 225-231. [CrossRef]

19. Li, Z.; Wang, A.; Chang, C.; Wang, Y.; Dong, B.; Zhou, S. Synthesis of FeSiBPNbCu nanocrystalline soft-magnetic alloys with high saturation magnetization. J. Alloy. Compd. 2014, 611, 197-201. [CrossRef]

20. Chang, C.; Qin, C.; Makino, A.; Inoue, A. Enhancement of glass-forming ability of FeSiBP bulk glassy alloys with good soft-magnetic properties and high corrosion resistance. J. Alloy. Compd. 2012, 533, 67-70. [CrossRef]

21. Miao, X.F.; Wang, Y.G.; Guo, M. Structural, thermal and magnetic properties of Fe-Si-B-P-Cu melt-spun ribbons: Application of non-isothermal kinetics and the amorphous random anisotropy model. J. Alloy. Compd. 2011, 509, 2789-2792. [CrossRef]

22. Ayers, J.; Harris, V.; Sprague, J.; Elam, W.; Jones, H. On the formation of nanocrystals in the soft magnetic alloy $\mathrm{Fe}_{73.5} \mathrm{Nb}_{3} \mathrm{Cu}_{1} \mathrm{Si}_{13.5} \mathrm{~B}_{9}$. Acta Mater. 1998, 46, 1861-1874. [CrossRef]

23. Nutor, R.K.; Xu, X.J.; Fan, X.Z.; He, X.W.; Lu, X.N.; Fang, Y.Z. Effects of applying tensile stress during annealing on the GMI and induced anisotropy of Fe-Cu-Nb-Si-B alloys. J. Magn. Magn. Mater. 2019, 471, 544-548. [CrossRef]

24. Ohnuma, M.; Hono, K.; Onodera, H.; Pedersen, J.; Linderoth, S. Cu clustering stage before the crystallization in $\mathrm{Fe}-\mathrm{Si}-\mathrm{B}-\mathrm{Nb}-\mathrm{Cu}$ amorphous alloys. Nanostruct. Mater. 1999, 12, 693-696. [CrossRef] 
25. Liu, Q.L.; Mo, J.Y.; Liu, H.S.; Xue, L.; Hou, L.; Yang, W.M.; Dou, L.T.; Shen, B.L.; Dou, L.M. Effects of Cu substitution for $\mathrm{Nb}$ on magnetic properties of Fe-based bulk metallic glasses. J. Non-Cryst. Solids. 2016, 443, 108-111. [CrossRef]

26. Hono, K.; Ping, D. Atom probe studies of nanocrystallization of amorphous alloys. Mater. Charact. 2000, 44, 203-217. [CrossRef]

27. Yang, W.M.; Liu, H.S.; Fan, X.D.; Xue, L.; Dun, C.C.; Shen, B.L. Enhanced glass forming ability of Fe-based amorphous alloys with minor $\mathrm{Cu}$ addition. J. Non-Cryst. Solids. 2015, 419, 65-68. [CrossRef]

28. Hono, K.; Inoue, A.; Sakurai, T. Atom probe analysis of $\mathrm{Fe}_{73.5} \mathrm{Si}_{13.5} \mathrm{~B}_{9} \mathrm{Nb}_{3} \mathrm{Cu}_{1}$ nanocrystalline soft magnetic material. Appl. Phys. Lett. 1991, 58, 2180-2182. [CrossRef]

29. Inoue, A.; Masumoto, T.; Chen, $\mathrm{H}$. Enthalpy relaxation behaviour of ( $\mathrm{Fe}, \mathrm{Co}, \mathrm{Ni}){ }_{75} \mathrm{Si}_{10} \mathrm{~B}_{15}$ amorphous alloys upon low temperature annealing. J. Mater. Sci. 1984, 19, 3953-3966. [CrossRef]

30. Ohta, M.; Yoshizawa, Y. High Bs nanocrystalline $\mathrm{Fe}_{84-x-y} \mathrm{Cu}_{x} \mathrm{Nb}_{y} \mathrm{Si}_{4} \mathrm{~B}_{12}$ alloys $(x=0.0-1.4, y=0.0-2.5)$. J. Magn. Magn. Mater. 2009, 321, 2220-2224. [CrossRef]

31. Ohta, M.; Yoshizawa, Y. Cu addition effect on soft magnetic properties in Fe-Si-B alloy system. J. Appl. Phys. 2008, 103, 07E722. [CrossRef]

32. Ohta, M.; Yoshizawa, Y. Improvement of Soft Magnetic Properties in $\left(\mathrm{Fe}_{0.85} \mathrm{~B}_{0.15}\right)_{100-x} \mathrm{Cu}_{x}$ Melt-Spun Alloys. Mater. Trans. 2007, 48, 2378-2380. [CrossRef]

(C) 2019 by the authors. Licensee MDPI, Basel, Switzerland. This article is an open access article distributed under the terms and conditions of the Creative Commons Attribution (CC BY) license (http://creativecommons.org/licenses/by/4.0/). 